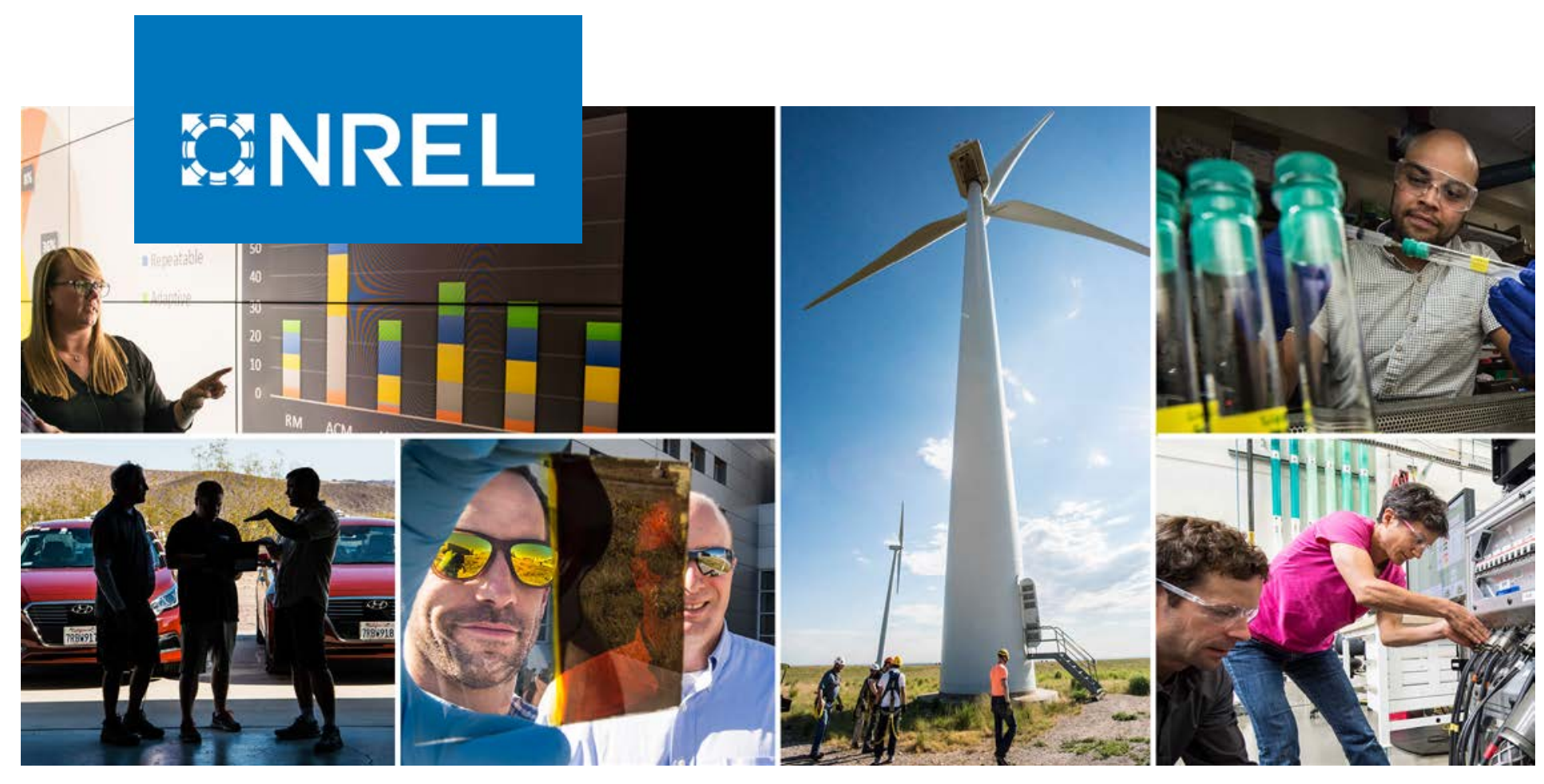

\title{
Weatherization Crew Leader Job Task Analysis
}

Chuck Kurnik ${ }^{1}$ and Sean Gasperson ${ }^{2}$

1 National Renewable Energy Laboratory

2 Castle Worldwide Inc.

NREL is a national laboratory of the U.S. Department of Energy

Office of Energy Efficiency \& Renewable Energy

Operated by the Alliance for Sustainable Energy, LLC

This report is available at no cost from the National Renewable Energy Laboratory (NREL) at www.nrel.gov/publications.

\section{Technical Report}

NREL/TP-7A40-73578

June 2019 


\section{FANEL}

\section{Weatherization Crew Leader Job Task Analysis}

Chuck Kurnik $^{1}$ and Sean Gasperson ${ }^{2}$

1 National Renewable Energy Laboratory

2 Castle Worldwide Inc.

Suggested Citation

Kurnik, Chuck and Sean Gasperson. 2019. Job Task Analysis Report Weatherization

Crew Leader. Golden, CO: National Renewable Energy Laboratory.

NREL/TP-7A40-73578. https://www.nrel.gov/docs/fy19osti/73578.pdf.

NREL is a national laboratory of the U.S. Department of Energy Office of Energy Efficiency \& Renewable Energy Operated by the Alliance for Sustainable Energy, LLC

This report is available at no cost from the National Renewable Energy Laboratory (NREL) at www.nrel.gov/publications.

Contract No. DE-AC36-08GO28308
Technical Report NREL/TP-7A40-73578 June 2019

National Renewable Energy Laboratory 15013 Denver West Parkway Golden, CO 80401 303-275-3000 • www.nrel.gov 


\section{NOTICE}

This work was authored in part by the National Renewable Energy Laboratory, operated by Alliance for Sustainable Energy, LLC, for the U.S. Department of Energy (DOE) under Contract No. DE-AC36-08G028308. Funding provided by U.S. Department of Energy Office of Energy Efficiency and Renewable Energy Weatherization and Intergovernmental Programs Office. The views expressed herein do not necessarily represent the views of the DOE or the U.S. Government.

This report is available at no cost from the National Renewable Energy Laboratory (NREL) at www.nrel.gov/publications.

U.S. Department of Energy (DOE) reports produced after 1991 and a growing number of pre-1991 documents are available free via www.OSTI.gov.

Cover Photos by Dennis Schroeder: (clockwise, left to right) NREL 51934, NREL 45897, NREL 42160, NREL 45891, NREL 48097, NREL 46526.

NREL prints on paper that contains recycled content. 


\section{Acknowledgments}

The work described in this document was funded by the U.S. Department of Energy's (DOE) Weatherization Assistance Program (WAP) under the Guidelines for Home Energy Professionals project. The authors want to thank WAP and the home performance industry professionals who participated on the scheme committee and volunteered many hours of their time and expertise to develop the Crew Leader (CL) job task analysis and retrofit installer badges. 


\section{Table of Contents}

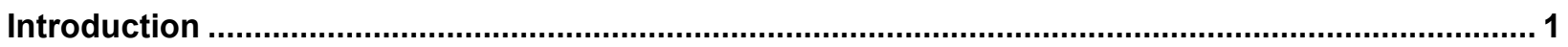

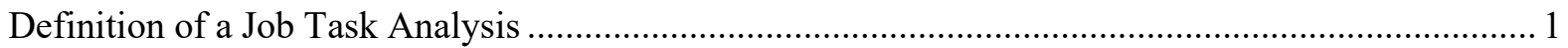

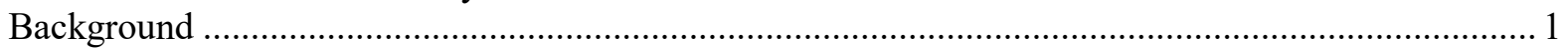

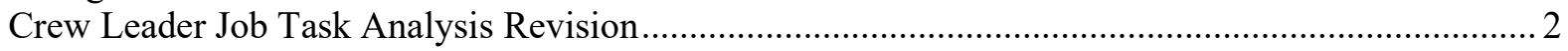

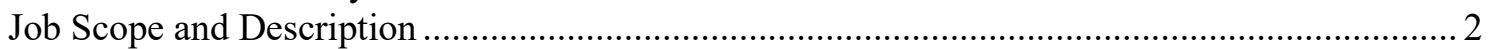

Final Crew Leader JTA and Examination Blueprint .................................................................... 2 


\section{Introduction}

The National Renewable Energy Laboratory (NREL) is contracted by the U.S. Department of Energy (DOE) Weatherization Assistance Program (WAP) to develop and maintain the resources under the Guidelines for Home Energy Professionals (GHEP) project. The purpose of the GHEP project is to increase the quality of work conducted for residential energy retrofits in the United States through the WAP network and other residential retrofit programs, NREL was tasked with developing GHEP resources that include the standard work specifications (SWS) and four advanced, competency-based home energy professionals (HEP) personnel certifications. Beginning in 2010 and continuing today, NREL has recruited more than 40 volunteer subject matter experts (SME) from the WAP network and the home performance industry to serve on committees to develop certification schemes and their requisite job task analysis (JTA) as the foundation of standardized certification and training programs.

As part of the GHEP strategy to increase the quality of work conducted for single-family, residential energy-efficiency retrofits, the HEP JTAs are used as the foundation for quality training programs and trainers. Accredited training programs ensure that individuals receive the proper training to do the quality work that is defined in the SWS. DOE contracted with the Interstate Renewable Energy Council (IREC) to develop an accreditation for energy-efficiency training programs based on the HEP JTAs. This accreditation is a third-party validation that an organization is qualified to teach the knowledge, skills, and abilities (KSA) outlined in the JTAs. This accredited training component of the GHEP project guarantees the existence and availability of high-quality standardized training programs within the home energy upgrade industry.

\section{Definition of a Job Task Analysis}

A JTA is a foundation for any valid credentialing program and helps identify the core knowledge areas, critical work functions, and/or skills typically found across a representative sampling of current practitioners or job incumbent workers. Empirical results from a job analysis provide examinees and the public with a valid, reliable, fair, and realistic assessment that reflects the knowledge, skills, and abilities required to competently perform a job.

\section{Background}

It is industry best practice to update a JTA approximately every 5 years. As part of the Crew Leader update effort in 2018, it was decided that the Retrofit Installer Technician (RIT) and Crew Leader (CL) JTA's would be combined into one comprehensive CL JTA. Combining the two JTA's stemmed from the fact that CLs regularly perform the same tasks as RITs, and CLs must be able to train RITs, in addition to the CL's supervisory tasks. Therefore, all knowledge and tasks that apply to RITs also apply to CLs.

The solution was to include the RIT role within the comprehensive CL JTA through the development of RIT badges. RIT badges would correspond to the tasks associated with the RIT role within the CL JTA. Completion of all RIT badges could be a prerequisite for CL exam, and candidates could earn badges in two ways either on the job, via a qualified supervisor, or by completing training and tasks at an accredited Weatherization Assistance Program (WAP) training center. 


\section{Crew Leader Job Task Analysis Revision}

A committee of 18 SMEs assembled by DOE and NREL met with trained psychometricians to delineate the roles of CL and RIT. The results of these meetings were used to update the CL JTA, create RIT badges which correspond to tasks within the CL JTA, and to create an exam blueprint. The existing RIT and CL JTAs were combined, reviewed, and revised to ensure that the knowledge and abilities measured by the CL examination reflect current practice in the field. In the fall of 2018, an online validation was performed to verify the results of the JTA and to finalize the examination blueprint. Ninety-five crew leaders from across the United States responded to the questionnaire.

\section{Job Scope and Description}

In addition to the CL JTA, the committee reviewed and combined the job scope and description for the CL into one comprehensive CL job description. The revised CL job description is as follows:

"A Crew Leader is responsible for supervising and assisting in the retrofitting activities specified in the scope of work. He or she is responsible for interacting with the client plus managing personnel and materials on the job site in a safe and effective manner. The Crew Leader is responsible for quality control, testing procedures, documentation, and conducting a walk through in preparation that all work is completed in a satisfactory manner."

Below is the final JTA with associated KSAs, integrated with the exam blueprint. If an entity wishes to create an exam based on the JTA, the exam blueprint is used to identify the percentage of exam questions dedicated to each Domain and Task.

\section{Final Crew Leader JTA and Examination Blueprint}

\begin{tabular}{|l|l|l|}
\hline Identifier & Content Area & $\begin{array}{l}\text { Exam } \\
\text { Weight }\end{array}$ \\
\hline D1. & Domain 1: Develop Plan to Execute Scope of Work & $\mathbf{1 6 . 5 \%}$ \\
\hline D1.T1 & Task 1: Identify materials and staffing needs. & $\mathbf{3 . 9 \%}$ \\
\hline D1.T1.K1 & Snowledge of: & \\
\hline D1.T1.K2 & Code compliance & \\
\hline D1.T1.K3 & Scope of work & \\
\hline D1.T1.K4 & Manufacturer specifications & \\
\hline D1.T1.K5 & Materials required & \\
\hline D1.T1.K6 & Personnel required & \\
\hline D1.T1.K7 & Physical parameters of the job & \\
\hline D1.T1.K8 & Schedule changes & \\
\hline D1.T1.K9 & Resources & \\
\hline D1.T1.K10 & SDS (Safety Data Sheet) & \\
\hline
\end{tabular}




\begin{tabular}{|c|c|c|}
\hline Identifier & Content Area & $\begin{array}{l}\text { Exam } \\
\text { Weight }\end{array}$ \\
\hline & Ability to: & \\
\hline D1.T1.A1 & Review and interpret scope of work & \\
\hline D1.T1.A2 & Integrate information from multiple sources & \\
\hline D1.T1.A3 & Assess crew and contractor capabilities & \\
\hline D1.T1.A4 & Estimate time required to complete each component of scope of work & \\
\hline D1.T1.A5 & Identify, select, and organize materials to complete scope of work & \\
\hline D1.T1.A6 & Estimate materials required & \\
\hline D1.T1.A7 & Determine appropriate tools and equipment to complete job & \\
\hline D1.T1.A8 & Track maintenance of tools and equipment & \\
\hline D1.T1.A9 & Report missing or deficient tools and materials & \\
\hline \multirow[t]{2}{*}{ D1.T2 } & Task 2: Prepare homeowner/occupants for the scope of work. & $3.9 \%$ \\
\hline & Knowledge of: & \\
\hline D1.T2.K1 & Safety protocols & \\
\hline D1.T2.K2 & Code compliance & \\
\hline D1.T2.K3 & Scope of work & \\
\hline \multirow[t]{2}{*}{ D1.T2.K4 } & Job site logistics & \\
\hline & Ability to: & \\
\hline D1.T2.A1 & Clearly communicate scope of work to a layperson & \\
\hline D1.T2.A2 & Provide documentation as needed & \\
\hline D1.T2.A3 & Review installation procedures & \\
\hline D1.T2.A4 & Identify preexisting conditions & \\
\hline D1.T2.A5 & Review scope of work & \\
\hline D1.T2.A6 & $\begin{array}{l}\text { Identify potential hazards to the client that may occur during work installation and } \\
\text { determine plan to avoid them }\end{array}$ & \\
\hline \multirow[t]{2}{*}{ D1.T3 } & Task 3: Determine readiness of the job site for the scope of work. & $3.6 \%$ \\
\hline & Knowledge of: & \\
\hline D1.T3.K1 & Safety protocols & \\
\hline D1.T3.K2 & Code compliance & \\
\hline D1.T3.K3 & Scope of work & \\
\hline D1.T3.K4 & Job site specifications & \\
\hline \multirow[t]{2}{*}{ D1.T3.K5 } & Prior hazards or barriers & \\
\hline & Ability to: & \\
\hline D1.T3.A1 & Confirm materials match work specifications & \\
\hline D1.T3.A2 & Identify materials and methods needed for job & \\
\hline
\end{tabular}




\begin{tabular}{|c|c|c|}
\hline Identifier & Content Area & $\begin{array}{l}\text { Exam } \\
\text { Weight }\end{array}$ \\
\hline D1.T3.A3 & Review scope of work & \\
\hline D1.T3.A4 & Confirm approval for state of work & \\
\hline D1.T3.A5 & Confirm completion of prerequisite work & \\
\hline \multirow[t]{2}{*}{ D1.T4 } & Task 4: Identify work site safety hazards and inform crew of safety requirements. & $5.1 \%$ \\
\hline & Knowledge of: & \\
\hline D1.T4.K1 & Safety protocols & \\
\hline D1.T4.K2 & Manufacturer specifications & \\
\hline D1.T4.K3 & Code compliance & \\
\hline \multirow[t]{2}{*}{ D1.T4.K4 } & Scope of work & \\
\hline & Ability to: & \\
\hline D1.T4.A1 & Assign safety responsibilities & \\
\hline D1.T4.A2 & Identify safety hazards & \\
\hline D1.T4.A3 & Conduct an effective safety meeting & \\
\hline D2 & Domain 2: Prepare and Maintain Job Site & $20.0 \%$ \\
\hline \multirow[t]{2}{*}{ D2.T1 } & Task 1: Locate and verify access to specific work areas. & $3.5 \%$ \\
\hline & Knowledge of: & \\
\hline D2.T1.K1 & Job site specifics & \\
\hline \multirow[t]{2}{*}{ D2.T1.K2 } & Scope of work & \\
\hline & Ability to: & \\
\hline D2.T1.A1 & Review the scope of work and job requirements & \\
\hline D2.T1.A2 & Confirm approval for start of work & \\
\hline D2.T1.A3 & $\begin{array}{l}\text { Work with crew lead to get access to areas (moving personal belongings, getting into } \\
\text { crawl space, etc.) }\end{array}$ & \\
\hline D2.T1.A4 & Create and/or repair access to work areas & \\
\hline \multirow[t]{2}{*}{ D2.T2 } & $\begin{array}{l}\text { Task 2: Protect interior/exterior of house (e.g. with drop cloths, poly, Tyvek } \\
\text { booties, pressurizations). }\end{array}$ & $4.3 \%$ \\
\hline & Knowledge of: & \\
\hline D2.T2.K1 & Job site specifics & \\
\hline D2.T2.K2 & Hazard containment & \\
\hline D2.T2.K3 & Safe practices & \\
\hline D2.T2.K4 & Scope of work & \\
\hline \multirow[t]{2}{*}{ D2.T2.K5 } & Drop cloths, tack mats & \\
\hline & Ability to: & \\
\hline D2.T2.A1 & Protect occupant belongings/property & \\
\hline D2.T2.A2 & Follow safe practices & \\
\hline
\end{tabular}




\begin{tabular}{|c|c|c|}
\hline Identifier & Content Area & $\begin{array}{l}\text { Exam } \\
\text { Weight }\end{array}$ \\
\hline \multirow[t]{2}{*}{ D2.T3 } & Task 3: Set up tools. & $4.4 \%$ \\
\hline & Knowledge of: & \\
\hline D2.T3.K1 & Safety protocols & \\
\hline D2.T3.K2 & Manufacturer specifications & \\
\hline \multirow[t]{2}{*}{ D2.T3.K3 } & Scope of work & \\
\hline & Ability to: & \\
\hline D2.T3.A1 & Properly stage tools & \\
\hline D2.T3.A2 & Verify operational status & \\
\hline D2.T3.A3 & Report deficiencies & \\
\hline \multirow[t]{2}{*}{ D2.T4 } & Task 4: Set up materials. & $3.7 \%$ \\
\hline & Knowledge of: & \\
\hline D2.T4.K1 & Job site specifics & \\
\hline D2.T4.K2 & Safety protocols & \\
\hline \multirow[t]{2}{*}{ D2.T4.K3 } & Scope of work & \\
\hline & Ability to: & \\
\hline D2.T4.A1 & Maintain integrity of materials & \\
\hline D2.T4.A2 & Report deficiencies & \\
\hline \multirow[t]{2}{*}{ D2.T5 } & Task 5: Report out of scope preexisting conditions & $4.1 \%$ \\
\hline & Knowledge of: & \\
\hline D2.T5.K1 & General construction & \\
\hline \multirow[t]{2}{*}{ D2.T5.K2 } & Scope of work & \\
\hline & Ability to: & \\
\hline D2.T5.A1 & Identify and report preexisting condition (aesthetic/structural) & \\
\hline D3 & Domain 3: Implement Scope of Work & $37.8 \%$ \\
\hline \multirow[t]{2}{*}{ D3.T1 } & Task 1: Identify and report potential combustible safety hazards. & $5.3 \%$ \\
\hline & Knowledge of: & \\
\hline D3.T1.K1 & Combustion appliance exhaust venting systems & \\
\hline D3.T1.K2 & Safety protocols & \\
\hline D3.T1.K3 & Manufacturer specifications & \\
\hline D3.T1.K4 & Ventilation systems & \\
\hline D3.T1.K5 & Heat producing devices & \\
\hline \multirow[t]{2}{*}{ D3.T1.K6 } & Applicable building science & \\
\hline & Ability to: & \\
\hline D3.T1.A1 & Identify and report potential safety issues & \\
\hline
\end{tabular}




\begin{tabular}{|c|c|c|}
\hline Identifier & Content Area & $\begin{array}{l}\text { Exam } \\
\text { Weight }\end{array}$ \\
\hline \multirow[t]{2}{*}{ D3.T2 } & Task 2: Install roof penetrations and weatherproofing. & $3.8 \%$ \\
\hline & Knowledge of: & \\
\hline D3.T2.K1 & Safety protocols & \\
\hline D3.T2.K2 & General carpentry & \\
\hline D3.T2.K3 & Code compliance & \\
\hline D3.T2.K4 & Manufacturer specifications & \\
\hline D3.T2.K5 & Tools & \\
\hline D3.T2.K6 & Materials & \\
\hline D3.T2.K7 & Roofing components & \\
\hline \multirow[t]{2}{*}{ D3.T2.K8 } & Applicable building science & \\
\hline & Ability to: & \\
\hline D3.T2.A1 & Gather required materials to complete the task & \\
\hline D3.T2.A2 & Gather required tools to complete the task & \\
\hline D3.T2.A3 & Identify and repair leak sources & \\
\hline D3.T2.A4 & Remove roofing system & \\
\hline D3.T2.A5 & Install attic ventilation & \\
\hline D3.T2.A6 & Flash new penetrations & \\
\hline \multirow[t]{2}{*}{ D3.T3 } & Task 3: Rough in mechanical ventilation systems. & $3.4 \%$ \\
\hline & Knowledge of: & \\
\hline D3.T3.K1 & Safety protocols & \\
\hline D3.T3.K2 & Tools & \\
\hline D3.T3.K3 & Materials & \\
\hline D3.T3.K4 & Framing basics & \\
\hline D3.T3.K5 & Manufacturer specifications & \\
\hline D3.T3.K6 & Penetration locations and water proofing & \\
\hline \multirow[t]{2}{*}{ D3.T3.K7 } & Applicable building science & \\
\hline & Ability to: & \\
\hline D3.T3.A1 & Gather required materials to complete the task & \\
\hline D3.T3.A2 & Gather required tools to complete the task & \\
\hline D3.T3.A3 & Identify electrical safety components and hazards & \\
\hline D3.T3.A4 & Identify plumbing safety components and hazards & \\
\hline D3.T3.A5 & Remove old equipment & \\
\hline D3.T3.A6 & Cut openings in building materials & \\
\hline D3.T3.A7 & Install venting system and vent terminations & \\
\hline
\end{tabular}




\begin{tabular}{|c|c|c|}
\hline Identifier & Content Area & $\begin{array}{l}\text { Exam } \\
\text { Weight }\end{array}$ \\
\hline D3.T3.A8 & Install, air seal, and insulate duct & \\
\hline D3.T3.A9 & Identify when installation is complete & \\
\hline \multirow[t]{2}{*}{ D3.T4 } & Task 4: Assist with mechanical systems upgrades. & $2.9 \%$ \\
\hline & Knowledge of: & \\
\hline D3.T4.K1 & Safety protocols & \\
\hline D3.T4.K2 & Job site specifics & \\
\hline D3.T4.K3 & Manufacturer specifications & \\
\hline D3.T4.K4 & Code compliance & \\
\hline D3.T4.K5 & Duct installation and sealing requirements & \\
\hline D3.T4.K6 & Duct systems and air flow basics & \\
\hline D3.T4.K7 & Sheet metal basics & \\
\hline D3.T4.K8 & Tools & \\
\hline D3.T4.K9 & Materials & \\
\hline \multirow[t]{2}{*}{ D3.T4.K10 } & Applicable building science & \\
\hline & Ability to: & \\
\hline D3.T4.A1 & Identify electrical safety components and hazards & \\
\hline D3.T4.A2 & Identify plumbing safety components and hazards & \\
\hline D3.T4.A3 & Gather required materials to complete the task & \\
\hline D3.T4.A4 & Gather required tools to complete the task & \\
\hline D3.T4.A5 & Identify fuel system components & \\
\hline D3.T4.A6 & Assist in removal of old equipment & \\
\hline D3.T4.A7 & Rough in openings in building & \\
\hline D3.T4.A8 & Repair, air seal, and insulate ducted distribution systems & \\
\hline D3.T4.A9 & Assist in installation of combustion vent system exhaust & \\
\hline D3.T4.A10 & Clean/replace air filters & \\
\hline \multirow[t]{2}{*}{ D3.T5 } & Task 5: Install air sealing measures. & $3.7 \%$ \\
\hline & Knowledge of: & \\
\hline D3.T5.K1 & Safety protocols & \\
\hline D3.T5.K2 & Code compliance & \\
\hline D3.T5.K3 & Manufacturer specifications & \\
\hline D3.T5.K4 & Material capability, durability, and strength & \\
\hline D3.T5.K5 & Building envelope & \\
\hline D3.T5.K6 & Scope of work & \\
\hline D3.T5.K7 & Applicable building science & \\
\hline
\end{tabular}




\begin{tabular}{|c|c|c|}
\hline Identifier & Content Area & $\begin{array}{l}\text { Exam } \\
\text { Weight }\end{array}$ \\
\hline D3.T5.K8 & Tools & \\
\hline D3.T5.K9 & Materials & \\
\hline \multirow[t]{2}{*}{ D3.T5.K10 } & $\begin{array}{l}\text { How a blower door is used to determine building air leakage and identify envelope } \\
\text { leaks and bypasses }\end{array}$ & \\
\hline & Ability to: & \\
\hline D3.T5.A1 & Identify electrical safety hazards & \\
\hline D3.T5.A2 & Identify plumbing safety hazards & \\
\hline D3.T5.A3 & Identify leaks and bypasses in the building envelope & \\
\hline D3.T5.A4 & Gather required materials to complete the task & \\
\hline D3.T5.A5 & Gather required tools to complete the task & \\
\hline D3.T5.A6 & Block large openings & \\
\hline D3.T5.A7 & Seal leaks and bypasses in the building envelope & \\
\hline D3.T5.A8 & Verify that air sealing is effective & \\
\hline D3.T5.A9 & Remove and replace insulation & \\
\hline \multirow[t]{2}{*}{ D3.T6 } & Task 6: Install or repair vapor retarders. & $3.1 \%$ \\
\hline & Knowledge of: & \\
\hline D3.T6.K1 & Safety protocols & \\
\hline D3.T6.K2 & Manufacturer specifications & \\
\hline D3.T6.K3 & Tools & \\
\hline D3.T6.K4 & Materials & \\
\hline D3.T6.K5 & Code compliance & \\
\hline D3.T6.K6 & Scope of work & \\
\hline D3.T6.K7 & Moisture source identification and control & \\
\hline \multirow[t]{2}{*}{ D3.T6.K8 } & Applicable building science & \\
\hline & Ability to: & \\
\hline D3.T6.A1 & Identify plumbing safety components and hazards & \\
\hline D3.T6.A2 & Remove all organic/inorganic materials & \\
\hline D3.T6.A3 & Gather required materials to complete the task & \\
\hline D3.T6.A4 & Gather required tools to complete the task & \\
\hline D3.T6.A5 & Install vapor retarder and seal joints and seams & \\
\hline D3.T6.A6 & Report moisture concerns & \\
\hline \multirow[t]{2}{*}{ D3.T7 } & Task 7: Install insulation. & $3.9 \%$ \\
\hline & Knowledge of: & \\
\hline D3.T7.K1 & Blower door testing & \\
\hline D3.T7.K2 & Building envelope & \\
\hline
\end{tabular}




\begin{tabular}{|c|c|c|}
\hline Identifier & Content Area & $\begin{array}{l}\text { Exam } \\
\text { Weight }\end{array}$ \\
\hline D3.T7.K3 & Code compliance & \\
\hline D3.T7.K4 & Coverage charts & \\
\hline D3.T7.K5 & Dense pack procedures & \\
\hline D3.T7.K6 & Depth markers & \\
\hline D3.T7.K7 & Drainage planes & \\
\hline D3.T7.K8 & Drill access points & \\
\hline D3.T7.K9 & Ducted distribution systems & \\
\hline D3.T7.K10 & Framing & \\
\hline D3.T7.K11 & General carpentry & \\
\hline D3.T7.K12 & Heat producing devices & \\
\hline D3.T7.K13 & Installation techniques & \\
\hline D3.T7.K14 & Insulation equipment & \\
\hline D3.T7.K15 & Limitations of components & \\
\hline D3.T7.K16 & Manufacturer specifications & \\
\hline D3.T7.K17 & Probing techniques & \\
\hline D3.T7.K18 & R-values & \\
\hline D3.T7.K19 & Safety protocols & \\
\hline D3.T7.K20 & Scope of work & \\
\hline D3.T7.K21 & Testing procedures & \\
\hline D3.T7.K22 & Type of building structures & \\
\hline D3.T7.K23 & Types of insulation materials and when to use them & \\
\hline \multirow[t]{2}{*}{ D3.T7.K24 } & Applicable building science & \\
\hline & Ability to: & \\
\hline D3.T7.A1 & Gather required materials to complete the task & \\
\hline D3.T7.A2 & Gather required tools to complete the task & \\
\hline D3.T7.A3 & Operate insulation equipment & \\
\hline D3.T7.A4 & Install insulation dams & \\
\hline D3.T7.A5 & Compare material use to coverage required (bags consumed) & \\
\hline D3.T7.A6 & Confirm air sealing is complete & \\
\hline D3.T7.A7 & Confirm building component integrity & \\
\hline D3.T7.A8 & Confirm clearance to combustibles & \\
\hline D3.T7.A9 & Confirm electrical is flagged & \\
\hline D3.T7.A10 & Confirm exhaust fans are ducted to outside and insulated & \\
\hline D3.T7.A11 & Confirm HVAC duct work is intact, sealed, supported, and insulated & \\
\hline
\end{tabular}




\begin{tabular}{|c|c|c|}
\hline Identifier & Content Area & $\begin{array}{l}\text { Exam } \\
\text { Weight }\end{array}$ \\
\hline D3.T7.A12 & Confirm vertical insulation & \\
\hline D3.T7.A13 & Fill all cavities & \\
\hline D3.T7.A14 & Fine tune machine for application (density) & \\
\hline D3.T7.A15 & Gain access to all building cavities, locate all horizontal blocks & \\
\hline D3.T7.A16 & Identify electrical safety components and hazards & \\
\hline D3.T7.A17 & Identify plumbing safety components and hazards & \\
\hline D3.T7.A18 & Install baffles, blocking, platforms, and insulation dams & \\
\hline D3.T7.A19 & Install horizontal insulation & \\
\hline D3.T7.A20 & Install vertical insulation & \\
\hline D3.T7.A21 & Locate drill points & \\
\hline D3.T7.A22 & Maintain rated $R$ values & \\
\hline D3.T7.A23 & Plug hole, patch weather barrier, put siding back, seal openings, caulk joints & \\
\hline D3.T7.A24 & Remove and replace various types of siding & \\
\hline D3.T7.A25 & Verify appropriate density & \\
\hline \multirow[t]{2}{*}{ D3.T8 } & Task 8: Install windows and doors. & $2.6 \%$ \\
\hline & Knowledge of: & \\
\hline D3.T8.K1 & Safety protocols & \\
\hline D3.T8.K2 & Manufacturer specifications & \\
\hline D3.T8.K3 & Code compliance & \\
\hline D3.T8.K4 & Scope of work & \\
\hline D3.T8.K5 & Drainage planes & \\
\hline D3.T8.K6 & Weatherproofing/flashing techniques & \\
\hline D3.T8.K7 & General carpentry & \\
\hline D3.T8.K8 & Tools & \\
\hline D3.T8.K9 & Materials & \\
\hline D3.T8.K10 & Window and door types & \\
\hline D3.T8.K11 & Vapor barriers & \\
\hline \multirow[t]{2}{*}{ D3.T8.K12 } & Applicable building science & \\
\hline & Ability to: & \\
\hline D3.T8.A1 & Gather required materials to complete the task & \\
\hline D3.T8.A2 & Gather required tools to complete the task & \\
\hline D3.T8.A3 & Remove old windows and doors & \\
\hline D3.T8.A4 & Check and install weatherproofing/ flashing & \\
\hline D3.T8.A5 & Install air barrier and ensure drainage & \\
\hline
\end{tabular}




\begin{tabular}{|c|c|c|}
\hline Identifier & Content Area & $\begin{array}{l}\text { Exam } \\
\text { Weight }\end{array}$ \\
\hline \multirow{2}{*}{ D3.T9 } & Task 9: Install baseload measures. & $2.5 \%$ \\
\hline & Knowledge of: & \\
\hline D3.T9.K1 & Safety protocols & \\
\hline D3.T9.K2 & Manufacturer specifications & \\
\hline D3.T9.K3 & Code compliance & \\
\hline D3.T9.K4 & Scope of work & \\
\hline D3.T9.K5 & Tools & \\
\hline D3.T9.K6 & Materials & \\
\hline \multirow[t]{2}{*}{ D3.T9.K7 } & Applicable building science & \\
\hline & Ability to: & \\
\hline D3.T9.A1 & Gather required materials to complete the task & \\
\hline D3.T9.A2 & Gather required tools to complete the task & \\
\hline D3.T9.A3 & Follow manufacturer specifications & \\
\hline \multirow[t]{2}{*}{ D3.T10 } & Task 10: Identify and report deviations from scope of work. & $3.0 \%$ \\
\hline & Knowledge of: & \\
\hline D3.T10.K1 & Scope of work & \\
\hline \multirow[t]{2}{*}{ D3.T10.K2 } & Applicable building science & \\
\hline & Ability to: & \\
\hline D3.T10.A1 & Identify deviation & \\
\hline D3.T10.A2 & Report deviation & \\
\hline D3.T10.A3 & Request direction for modified scope of work & \\
\hline D3.T10.A4 & Implement modified scope of work & \\
\hline \multirow[t]{2}{*}{ D3.T11 } & Task 11: Clean all debris and work materials from the job site. & $3.8 \%$ \\
\hline & Knowledge of: & \\
\hline D3.T11.K1 & Safety protocols & \\
\hline D3.T11.K2 & Hazard containment and disposal procedures & \\
\hline D3.T11.K3 & Recyclable materials & \\
\hline D3.T11.K4 & Materials SDS (Safety Data Sheet) & \\
\hline D3.T11.K5 & Tool inventory & \\
\hline \multirow[t]{2}{*}{ D3.T11.K6 } & Applicable building science & \\
\hline & Ability to: & \\
\hline D3.T11.A1 & Remove containment & \\
\hline D3.T11.A2 & Properly contain, sort, transport, and dispose of materials and waste & \\
\hline
\end{tabular}




\begin{tabular}{|c|c|c|}
\hline Identifier & Content Area & $\begin{array}{l}\text { Exam } \\
\text { Weight }\end{array}$ \\
\hline D4 & Domain 4: Manage Project & $18.8 \%$ \\
\hline \multirow{2}{*}{ D4.T1 } & Task 1: Conduct diagnostic testing. & $4.4 \%$ \\
\hline & Knowledge of: & \\
\hline D4.T1.K1 & Safety protocols & \\
\hline D4.T1.K2 & Manufacturer specifications & \\
\hline D4.T1.K3 & Code compliance & \\
\hline D4.T1.K4 & Scope of work & \\
\hline D4.T1.K5 & Diagnostic equipment testing procedures & \\
\hline \multirow[t]{2}{*}{ D4.T1.K6 } & $\begin{array}{l}\text { When tests are necessary, e.g., conducting combustion safety test-out after any work } \\
\text { that might impact draft, before leaving house }\end{array}$ & \\
\hline & Ability to: & \\
\hline D4.T1.A1 & Perform blower door air leakage testing & \\
\hline D4.T1.A2 & Perform combustion safety testing & \\
\hline D4.T1.A3 & Conduct IR scans & \\
\hline D4.T1.A4 & Conduct room to room pressure testing & \\
\hline D4.T1.A5 & Interpret and document the testing results & \\
\hline D4.T1.A6 & Compare results to jurisdiction requirements & \\
\hline \multirow[t]{2}{*}{ D4.T2 } & Task 2: Adjust scope of work as needed to reflect current conditions. & $3.1 \%$ \\
\hline & Knowledge of: & \\
\hline D4.T2.K1 & Safety protocols & \\
\hline D4.T2.K2 & Code compliance & \\
\hline D4.T2.K3 & Scope of work & \\
\hline D4.T2.K4 & Building techniques & \\
\hline D4.T2.K5 & Building science & \\
\hline D4.T2.K6 & Building materials & \\
\hline \multirow[t]{2}{*}{ D4.T2.K7 } & Required forms and documentation & \\
\hline & Ability to: & \\
\hline D4.T2.A1 & Document changes or agreements with responsible party in writing as necessary & \\
\hline D4.T2.A2 & Interpret scope of work & \\
\hline D4.T2.A3 & Integrate information from multiple sources & \\
\hline D4.T2.A4 & Estimate time required & \\
\hline D4.T2.A5 & Estimate materials required & \\
\hline D4.T2.A6 & Communicate changes properly through chain of command & \\
\hline D4.T2.A7 & Identify deviations from the scope of work & \\
\hline D4.T2.A8 & Set expectations with the responsible party regarding scope of work changes & \\
\hline
\end{tabular}




\begin{tabular}{|c|c|c|}
\hline Identifier & Content Area & $\begin{array}{l}\text { Exam } \\
\text { Weight }\end{array}$ \\
\hline D4.T2.A9 & Process forms and documentation & \\
\hline \multirow[t]{2}{*}{ D4.T3 } & $\begin{array}{l}\text { Task 3: Post necessary paperwork, (e.g. permits, lead-based paint EPA } \\
\text { requirements, historic preservation). }\end{array}$ & $3.4 \%$ \\
\hline & Knowledge of: & \\
\hline D4.T3.K1 & Safety protocols & \\
\hline D4.T3.K2 & Code compliance & \\
\hline D4.T3.K3 & Scope of work & \\
\hline D4.T3.K4 & Posting requirements of permits, certificates, and signage & \\
\hline \multirow[t]{2}{*}{ D4.T4 } & Task 4: Monitor safety practices. & $4.7 \%$ \\
\hline & Knowledge of: & \\
\hline D4.T4.K1 & Safety protocols & \\
\hline D4.T4.K2 & Manufacturer specifications & \\
\hline D4.T4.K3 & Code compliance & \\
\hline \multirow[t]{2}{*}{ D4.T4.K4 } & Scope of work & \\
\hline & Ability to: & \\
\hline D4.T4.A1 & Recognize noncompliance with safety protocols & \\
\hline D4.T4.A2 & Enforce safety protocols & \\
\hline D4.T4.A3 & Make onsite corrections to ensure safety & \\
\hline \multirow[t]{2}{*}{ D4.T5 } & $\begin{array}{l}\text { Task 5: Maintain and document project progression, personnel control, and } \\
\text { compliance. }\end{array}$ & $3.3 \%$ \\
\hline & Knowledge of: & \\
\hline D4.T5.K1 & Safety protocols & \\
\hline D4.T5.K2 & Manufacturer specifications & \\
\hline D4.T5.K3 & Code compliance & \\
\hline D4.T5.K4 & Scope of work & \\
\hline D4.T5.K5 & Material disposal requirements & \\
\hline D4.T5.K6 & Appropriate forms and written documentation & \\
\hline D4.T5.K7 & Prerequisite and individual tasks that make up the scope of work & \\
\hline D4.T5.K8 & Capabilities and limitations of members of the crew and contractors & \\
\hline \multirow[t]{2}{*}{ D4.T5.K9 } & Required standards and procedures & \\
\hline & Ability to: & \\
\hline D4.T5.A1 & $\begin{array}{l}\text { Verify that all components of a day's scope of work have been completed and cleaned } \\
\text { up appropriately }\end{array}$ & \\
\hline D4.T5.A2 & Conduct a visual inspection & \\
\hline D4.T5.A3 & Monitor and adjust use of resources & \\
\hline D4.T5.A4 & Supervise work in progress & \\
\hline
\end{tabular}




\begin{tabular}{|c|c|c|}
\hline Identifier & Content Area & $\begin{array}{l}\text { Exam } \\
\text { Weight }\end{array}$ \\
\hline D4.T5.A5 & Prioritize activities of crew & \\
\hline D4.T5.A6 & $\begin{array}{l}\text { Confirm and document with notes or images that assigned tasks are completed (e.g. } \\
\text { quantities, materials used, who completed the task, sign off, pictures) }\end{array}$ & \\
\hline D4.T5.A7 & Identify and explain deviations of the scope of work & \\
\hline D4.T5.A8 & Gain permission(s) to revise and adjust scope of work as appropriate & \\
\hline D4.T5.A9 & Provide corrective actions as necessary & \\
\hline D5 & Domain 5: Finalize Job & $6.9 \%$ \\
\hline \multirow[t]{2}{*}{ D5.T1 } & $\begin{array}{l}\text { Task 1: Verify that all components of the scope of work have been completed in } \\
\text { compliance with required codes and standards. }\end{array}$ & $3.8 \%$ \\
\hline & Knowledge of: & \\
\hline D5.T1.K1 & Safety protocols & \\
\hline D5.T1.K2 & Manufacturer specifications & \\
\hline D5.T1.K3 & Code compliance & \\
\hline D5.T1.K4 & Scope of work & \\
\hline D5.T1.K5 & Diagnostic equipment & \\
\hline D5.T1.K6 & Data collection & \\
\hline D5.T1.K7 & Required standards and procedures & \\
\hline D5.T1.K8 & Hazard containment & \\
\hline D5.T1.K9 & Applicable building science & \\
\hline \multirow[t]{2}{*}{ D5.T1.K10 } & Required signatures & \\
\hline & Ability to: & \\
\hline D5.T1.A1 & Use diagnostic equipment & \\
\hline D5.T1.A2 & $\begin{array}{l}\text { Evaluate a project for compliance with program or policy requirements and applicable } \\
\text { codes and standards }\end{array}$ & \\
\hline D5.T1.A3 & Verify that all debris and work materials have been cleaned from the job site & \\
\hline D5.T1.A4 & Review scope of work with responsible party & \\
\hline D5.T1.A5 & Provide client education according to specified standards of quality and performance & \\
\hline D5.T1.A6 & Communicate project close out (product manuals, utility rebates, next steps, etc.) & \\
\hline D5.T1.A7 & $\begin{array}{l}\text { Verify placement of all required insulation certificates and that client has received } \\
\text { copies of user manuals for any equipment installed }\end{array}$ & \\
\hline D5.T1.A8 & Perform walk through with homeowner/responsible party & \\
\hline D5.T1.A9 & Obtain homeowner/responsible party job-completion sign-off signatures as required & \\
\hline \multirow[t]{2}{*}{ D5.T2 } & $\begin{array}{l}\text { Task 2: Complete all post-work documentation as required (e.g. materials, labor } \\
\text { hours, photos, certified renovator signatures, information for inspectors). }\end{array}$ & $3.1 \%$ \\
\hline & Knowledge of: & \\
\hline D5.T2.K1 & Code compliance & \\
\hline D5.T2.K2 & Scope of work & \\
\hline
\end{tabular}




\begin{tabular}{|l|l|l|}
\hline Identifier & Content Area & $\begin{array}{l}\text { Exam } \\
\text { Weight }\end{array}$ \\
\hline D5.T2.K3 & Required documentation & \\
\hline & Ability to: & \\
\hline D5.T2.A1 & Integrate or record information from multiple sources & \\
\hline
\end{tabular}

